Article Type: Clinical Article

\title{
Determinants in the process of seeking help for urinary incontinence in the
}

\section{Chilean health system}

Carolina Bascur-Castillo ${ }^{1,2}$, Valentina Araneda-Gatica ${ }^{3}$, Henry Castro-Arias ${ }^{2,5}$, Mercedes Carrasco-Portiño ${ }^{1,4^{*}}$, María Teresa Ruiz-Cantero ${ }^{5,6}$

${ }^{1}$ Department of Obstetrics and Puericulture. Faculty of Medicine, University of Concepción, Concepción, Chile

${ }^{2}$ Pelvic Floor Unit. Dr. Guillermo Grant Benavente Hospital, Concepción, Chile

${ }^{3}$ Service of Obstetrics and Gynecology. Hospital of Tomé, Tomé, Chile

${ }^{4}$ Research Group on Public Health. University of Alicante, Alicante, Spain

${ }^{5}$ Department of Obstetrics and Gynecology. Faculty of Medicine, University of

Concepción, Concepción, Chile

${ }^{6}$ CIBER de Epidemiología y Salud Púbica, Barcelona, Spain.

\section{* Correspondence: Mercedes Carrasco-Portiño}

Departamento de Obstetricia y Puericultura, Facultad de Medicina, Universidad de Concepción, Avda Chacabuco esquina Janequeo s/n. 3er piso, Concepción, Chile E-mail: mecarrasco@udec.cl

This article has been accepted for publication and undergone full peer review but has not been through the copyediting, typesetting, pagination and proofreading process, which may lead to differences between this version and the Version of Record. Please cite this article as doi: 10.1002/ijgo.12685

This article is protected by copyright. All rights reserved. 
Synopsis: Factors involved in the process of seeking help for urinary incontinence in Chilean health system are identified through a dynamic model with different levels.

Keywords: Health services accessibility; Patient acceptance of health care;

Qualitative research; Quality of life; Stress urinary incontinence; Urinary incontinence; Urge urinary incontinence

\begin{abstract}
Objective: To analyze via the Andersen model what leads women with urinary incontinence $(\mathrm{UI})$ to seek help and remain in the health care system.
\end{abstract}

Methods: An interpretative phenomenologic study enrolling women aged 18 years or older who were diagnosed with $\mathrm{UI}$ at a tertiary care hospital in Chile between January and March 2016. Data were collected by semi-structured interview. The categories explored experience with $\mathrm{UI}$ and reasons for seeking health care, and included the dimensions of the Andersen model.

Results: Ten women were enrolled. Characteristics that eased or hindered healthcare seeking were identified to come from the women (frequency and quantity of symptoms, coping strategies, and beliefs about its causes) and from their environment (reaction of partner, family, or coworkers to her condition). Some were associated with primary care (human and/or technical resources) and some with secondary care (pelvic floor units).

Conclusion: The results reflect the complexities of asking for health care for women with $\mathrm{UI}$, especially in a country such as Chile with different healthcare levels. Raising awareness of this complexity and developing an approach that includes all 
stakeholders (institution, community, and family) is crucial for professionals who want to offer both medical therapy and wellness-focused healthcare.

\section{INTRODUCTION}

One of the most prevalent pelvic floor dysfunctions in women is urinary incontinence (UI), which is associated with several risk factors [1]. It is calculated to affect $17 \%-$ $67.2 \%$ of women aged 18 years or older [1-4]. UI has a great impact on quality of life [4]. On experiencing the first symptoms of urinary incontinence, women face different variables that affect seeking healthcare and access [4], including embarrassment about leakage and believing that the symptoms are normal [5-7], low expectations regarding health professionals, ignorance about treatment options, and taking steps to adapt their daily routine to UI [7].

Different theoretic models have been developed to identify the decision-taking process for seeking health care $[8,9]$. One of the most used models is that of Ronald Max Andersen [8], which attempts to explain the use of health systems. This model proposes that use depends on three types of factor: predisposing factors, which are unique to each patient and do not depend on their disease; enabling factors, which ease or hinder access to health systems and depend on changes on health policies; and the patient's needs, including perception and severity of the disease symptoms $[8,10]$.

The Andersen model does not take into account different level of care, such as those offered for women's health in the Chilean health system: namely, primary care for preventing and promoting gynecologic health; secondary care for specialized 
pharmacologic or conservative treatment (e.g., pelvic floor units); and tertiary care for surgery and physical therapy [11]. For that reason, the aim of the present study was to analyze, via the Andersen model, the determinants of the decisions of women with UI to seek medical attention and remain in the health system for treatment.

\section{MATERIALS AND METHODS}

The present qualitative study, based on an phenomenologic interpretativeexplanatory method, enrolled women treated at a pelvic floor unit of a tertiary care hospital in southern Chile between January 1 and March 31 2016. The study was evaluated and approved (June 7, 2014) by the Research Ethics Committee of the Health Service of Concepción, which is accredited by the Ministry of Health of Chile. All participants provided informed consent.

The study population was determined by theoretic sampling, with a focus on intention and flexibility. Relevance validity was ensured by using maximum variation sampling, identifying a total of 10 women, none of whom refused to participate in the study.

The inclusion criteria were age 18 years or older and a diagnosis of with UI (stress, urge, or mixed) at the pelvic floor unit that had yet to be treated. The exclusion criterion was any psychiatric or neurologic pathology that would hinder effective communication during the interview.

Participants were identified with the help of a midwife (Chilean midwives specialize in sexual and reproductive health) by reviewing medical files at the pelvic floor unit. 
After giving informed consent, participants were interviewed in a hospital room, which was adapted to ensure patient privacy. Depending on the woman's availability, some interviews were done immediately after the clinic visit, but others were scheduled for a later date.

Data were collected by semi-structured interview, which incorporated dimensions associated with the participant's experience at the pelvic floor unit and their reasons for seeking care in the health system, including the three dimensions of Andersen: namely, predisposing factors; enabling factors; and patient needs $[9,10]$.

Interviews were recorded and transcribed literally using Office software (Microsoft, Redmond, WA, USA). The data were then codified for triangulation. Next, common elements were re-codified, with priority given to those with more significance, facilitating better interpretation and ensuring the viability of the analysis.

A second triangulation was carried out by three of the four researchers, removing any potential bias and ensuring reliable observations. Triangulation among the research team members, discourse saturation, and external audit ensured the reliability of the study.

\section{RESULTS}

The age of the 10 participants ranged from 33 to 53 years; the most common age was $40-50$ years. Their educational attainment ranged from primary school $(n=2)$ to secondary school $(n=4)$ and college education $(n=4)$. More than half of the participants $(n=6)$ had a remunerated job (teacher, nursery technician, domestic 
worker, and vendor), whereas the rest were housewives without payment. Nine out of ten women had children, with an average of three (range 0-4). In total, there were 22 deliveries, 14 (64\%) of which were vaginal with episiotomy. Newborn weight fluctuated between 2075 and $4800 \mathrm{~g}$; two neonates weighed more than $4000 \mathrm{~g}$. The duration between symptoms being identified to the first visit to a doctor varied from 4 months to 19 years; $1-5$ years was the most frequent waiting time $(n=5)$ (Table 1$)$.

Analysis of the content of the interviews identified several common characteristics, some of which had been previously identified and others of which were noted only when the data were collected. The first group of common characteristics includes those associated with the women themselves that may have an influence on their healthcare seeking process, either by enabling it (i.e., patient doubt about the development of the disease) or hindering it (i.e., their beliefs about its causes, postponing their own needs, and adaptation mechanisms to compensate for the leakages). In addition, depending on their extent, some of the characteristics can either ease or hinder healthcare seeking (i.e., their own evaluation of symptom frequency and quantity) (Table 2).

The second group of characteristics are associated with the women's environment: namely, the reactions of their partners, families, friends, and coworkers to their UI. As before, some of these characteristics enable seeking health care (i.e., the disdain of their support network, or strong familiar and social support), while others hinder it (i.e., lack of interest by their support network) (Table 3).

This article is protected by copyright. All rights reserved. 
The third group of characteristics are associated with primary care: namely, elements that are related to human or technical resources in primary care centers. As before, these characteristics may enable (i.e., professionals with gynecologic training who can give personalized support, or specific programs on preventive and promotional gynecologic care) or hinder (i.e., lack of informative campaigns about pelvic floor dysfunction that might raise awareness among the population at risk) women who are seeking health care (Table 4).

The last group of characteristics are associated with secondary care: namely, the pelvic floor units in tertiary care hospitals. Again, some characteristics ease the patient's permanence in this care level (i.e., receiving information about their diagnosis and its causes, and staff empathy and commitment), whereas others hinder it (i.e., short visits from the specialist, misguided concepts of the service, long waiting times, and appointment times that are not respected) (Table 5).

\section{DISCUSSION}

The present study women with UI are individuals with their own reasons and intentions, as demonstrated in their discourse. They make rational decisions, depending on the balance between symptom frequency/quantity and its impact on their daily activities. Despite their threatened integrity, they admit to having limited autonomy when seeking health care, owing to ignorance and misguided beliefs about their environment. In this process, women are pragmatic decision-makers, taking into account both the factors that ease their access to health services, such as availability of trained professionals and coordination among healthcare levels, and the factors that hinder it, such as delayed access to health services and a below-par care service.

This article is protected by copyright. All rights reserved. 
The socio-demographic characteristics of the study women match the reported profile of women with UI [1]. In fact, UI rates are higher among women of the age group reported here (33-53 years), especially among those with decreased estrogen levels after the menopause. Most of the current women had had vaginal deliveries, which is the main risk factor associated with $\mathrm{UI}$, and some women had had an episiotomy, which increases the probability of developing UI [12]. Similarly, newborn weight and the number of deliveries are risk factors for UI [13], indicating that the current study sample represents a typical group of UI patients.

Although the Andersen model has not been used in studies of pelvic floor dysfunction, research from the USA, Australia, Germany, and the United Kingdom have variously used it to explain patient access to health systems [14-17]. In some studies, the cost of medical care was identified as part of the patient's needs in the Andersen model, leading to healthcare seeking; in other words, it belonged to the dimension focused on the perception and seriousness of the disease symptoms $[14,15]$. In another study, the Andersen model led to an understanding of how environmental and personal factors affect the health behavior of individuals infected with HIV, leading to better interventions for retaining these patients in the health system and in treatment [16].

A systematic review found that the dimension of patient needs and enabling factors that ease or hinder access to health systems—and depend on health policies-are key determinants of a delayed cancer diagnosis [17]. The review confirmed that there are clearly recognizable stages in the time period that covers finding a 
symptom, the first visit to a health professional, receiving the diagnosis, and starting the treatment. Clear evidence supports the existence and importance of evaluating delayed treatment as defined by Andersen, although the findings suggested that the model should be refined in order to improve its validity and use for different pathologies [17].

Although the Andersen model provided an approach to the factors affecting health service access by patients in the present pelvic floor unit in southern Chile, not all elements were captured by the model, especially the different healthcare levels and the dynamism seen in the patients' discourse. Therefore, we propose a dynamic model that recognizes the process of seeking health care and remaining in the system and includes four levels: personal characteristics, environment, primary health care, and specialized health care. Within these levels, there are characteristics that can ease or hinder the whole process (Figure 1).

The revised model has several elements in common with the Andersen model. The personal characteristics identified in the present study fit with the predisposing and personal need factors that Andersen proposed. In this level, personal characteristics associated with previous knowledge (beliefs about the cause of the symptoms) and with patient behavior (postponing a checkup or adapting to the symptoms) and emotional response (doubt) when experiencing leakages were identified. If primary healthcare teams were able to identify these beliefs in a patient, they would be able to dispel them while offering direct care, and to improve educational campaigns on gynecologic health with a special focus on the population at risk [18-21]: both measures are recognized as strengths of primary health care [22]. 
The patient's needs in the Andersen's model, or the patient's perception of their own health, includes their assessment of the frequency and quantity of their symptoms. Its importance lies in that this assessment can ease the process of seeking health care if the symptoms mean a general alteration of quality of life; however, if the symptoms do not have a significant impact on daily activities, this assessment can hinder the process $[6,23]$.

The second level, containing environmental factors, involves other individuals including partners, families, friends, and/or colleagues. Their reaction to UI symptoms can ease the process: for example, if they ridicule the patients or treat them with contempt, as reflected in the participants' responses, the women may feel that it is necessary to seek help so that they do not experience such rejection again [24]. However, their reaction can also hinder the process, especially for women who live in a restrictive cultural context, if their ignorance or misguided beliefs make the women react with apathy to their symptoms [7, 25].

The third level of the proposed model has, as easing factors, the presence of at least one health professional trained in gynecologic care (i.e., midwives in Chile) and gynecologic healthcare programs with educational campaigns [26]. A lack of these factors might delay access to health care, leading to worse health and quality of life [20].

The last level of the proposed model includes specialized units and their coordination with primary care $[23,27]$, which, coupled with coupled with staff empathy and compromise, would facilitate the patient's stay within the healthcare system by 
reducing waiting times and providing information on the diagnosis and causes of UI. By contrast, a lack of continuous training and a less than excellent service might hinder the healthcare seeking process [28].

A strength of the proposed model is its dynamic condition, since it allows for actions that consider multidirectional progression that is mediated by the combination of facilitating and/or hindering factors at different healthcare levels. This contrasts with the Andersen model, which proposed more static predisposing factors [9, 10].

The study had some further strengths. Despite the small number of interviews, the population was diverse, encompassing a varied range of real situations: the women were aged 33-53 years, with primary to tertiary education, with paid or unpaid work, and with 0 to 4 children. Among the 22 deliveries, 14 had involved episiotomy, and the newborn weight ranged from 2700 to $4800 \mathrm{~g}$. Most importantly, the participants had waited between 4 months and 19 years before going to a health center for their UI symptoms. Therefore, the present findings represent profiles that differ from those traditionally reported in scientific studies, showing that this pathology affects women over a wide age range and not only those in perimenopause. Last, the study women came from different points in the region, not only from the urban area where the health center was located.

Another strength is that the study team has considerable experience in detecting, treating, and rehabilitating women with pelvic floor dysfunction, and with $\mathrm{UI}$ in particular, which will help disseminate the results to all healthcare levels at a local and national level and facilitate these women's access to timely health care. In 
addition, the team is part of tertiary health care, being in charge of final resolutions for patient pathology and seeking to establish a link with primary care in order to solve the problems identified in the present study. Last, it should be noted that the team has experience in researching and teaching this theme at undergraduate and postgraduate levels.

The study also has some limitations. First, it enrolled only women referred to the pelvic floor unit, and thus women who attended primary health care centers were not included. The latter women might experience other obstructing factors that do not let them access the higher care levels in the proposed model.

Second, the design of the proposed model is based on women with access to secondary health care; therefore, the experiences of women with risk factors who have yet to receive informative and preventive care are unknown and might enrich the model. Last, women aged more than 55 years, who have the highest prevalence of incontinence and are more likely to have restricted access to health care owing to reduced mobility or several pathologies, were omitted from the study. Thus, the model is mainly aimed at young women of childbearing age.

In conclusion, the study participants perceived different obstacles in accessing health care for UI, but they also recognized elements that facilitate the process. The findings have enabled the recognition of a dynamic model that identifies the process of seeking help for UI and remaining in the healthcare system through several decisive factors (personal characteristics, environment, primary care, and specialized care). The model will be a useful tool to improve the quality of healthcare 
services in treating pelvic floor dysfunction and identifies elements not included in the Andersen model, such as different healthcare levels. Nevertheless, more research is needed on the women who seek care at the primary healthcare level (i.e., family health centers in Chile) and have yet to be referred or to make the decision to go to secondary health care, is needed. This depends not only on healthcare staff or women with UI, but also on political initiatives for increasing investment in health in order to address pelvic floor dysfunction, which affects an important part of the female population.

The present results reflect how complex the situation is for women with UI when deciding to ask for health care, especially in a country such as Chile, where the differences among the healthcare levels are so distinct. Raising awareness of its complexity and developing an approach that equally includes all important stakeholders (institution, community, and family) is crucial for professionals who want to offer both medical therapy and wellbeing-focused health care. It is necessary to keep and strengthen a well-designed, coordinated, and viable referral system with trained professionals, as seen in the Chilean system, where specialized medical staff and midwives coexist in all three healthcare levels.

\section{Author contributions}

All authors contributed to study design, data analysis and interpretation, and writing and revision of the manuscript.

\section{Conflicts of interest}

The authors have no conflicts of interest. 


\section{References}

1. Schreiber Pedersen L. Prevalence of urinary incontinence among women and analysis of potential risk factors in Germany and Denmark. Acta Obstet Gynecol Scand 2017; 96:939-48

2. Walker G, Gunasekera P. Pelvic organ prolapse and incontinence in developing countries: review of prevalence and risk factors. Int Urogynecol J. 2011; 22(2): 127-35.

3. Wu J. Prevalence and trends of Symptomatic pelvic floor disorders in U.S. women. Obstet Gynecol 2014;123:141-8.

4. Sensoy N, Dogan N, Ozek B, et al. Urinary incontinence in women: prevalence rates, risk factors and impact on quality of life. Pak J Med Sci. 2013;29: 818-22.

5. Siddiqui N. Perceptions about female urinary incontinence: a systematic review. Int Urogynecol J. 2014;25:863-71.

6. Koch LH. Help-seeking behaviors of women with urinary incontinence: an integrative literature review. J Midwifery Womens Health. 2006;51(6):39-44

7. Perera J, Kirthinanda DS, Wijeratne S, et al. Descriptive cross sectional study on prevalence, perceptions, predisposing factors and health seeking behaviour of women with stress urinary incontinence. BMC Women's Health. 2014;14:78.

8. Frenk J. Concept and measurement of accessibility. Salud Pública Mex. 1985; $27(5): 438-53$.

9. Andersen RM. Revisiting the behavioral model and access to medical care: does it matter? J Health Soc Behav. 1995;36:1-10. 
10. Andersen RM. National Health Surveys and the Behavioral Model of Health Services Use. Annals of HSR. 2008;46(7):647-53.

11. Government of Chile. Ministry of Health. Undersecretariat of welfare networks. Primary Care Division. Guidelines for networked planning and programming, 2013. (Accessed September 24, 2018). Available from http://www.minsal.cl/portal/url/item/cd34d7da59bfbd48e0400101650154ea.pdf 12. Handa V. Pelvic Floor Disorders 5-10 Years After Vaginal or Cesarean Childbirth. Obstet Gynecol. 2011 October ; 118(4): 777-84

13. Gyhagen M. The prevalence of urinary incontinence 20 years after childbirth: a national cohort study in singlet on primiparae after vaginal or caesarean delivery. BJOG 2013;120:144-51

14. Lo T, Parkinson L, Cunich $\mathrm{M}$, et al. Factors associated with the health care cost in older Australian women with arthritis: an application of the Andersen's Behavioural Model of Health Services Use. Public Health. 2016;134:64-71. 15. Heider D, Matschinger $\mathrm{H}$, Müller $\mathrm{H}$, et al. Health care costs in the elderly in Germany: an analysis applying Andersen's behavioral model of health care utilization. BMC Health Serv Res. 2014; 14;14:71. (Accessed September 24, 2018). Available from https://www.ncbi.nlm.nih.gov/pmc/articles/PMC3927831/pdf/14726963-14-71.pdf.

16. Holtzman CW, Shea JA, Glanz K, et al. Mapping patient-identified barriers and facilitators to retention in HIV care and antiretroviral therapy adherence to Andersen's Behavioral Model. AIDS Care. 2015; 27(7): 817-28.

17. Walter F, Webster A, Scott S, et al. The Andersen Model of Total Patient Delay: a systematic review of its application in cancer diagnosis. Journal of Health Services Research \& Policy. 2012; 2:110-8. 
18. Minassian V, Yan $\mathrm{X}$, Lichtenfeld $\mathrm{M}$, et al. Predictors of care seeking in women with urinary incontinence. Neurourol Urodyn. 2012; 31(4):470-4

19. Higa R, Lopes MH, Turato ER. Psychocultural meanings of urinary incontinence in women: a review. Rev. Lat. Am. Enfermagem. 2008;16(4):779-86. 20. Volkmer C, Monticelli M, Reibnitz KS, et al. Female urinary incontinence: systematic review of qualitative studies. Cien Saude Colet. 2012; 17(10):2703-15. 21. Buurman MB, Lagro-Janssen AL. Women's perception of postpartum pelvic floor dysfunction and their help-seeking behaviour: a qualitative interview study. Scand J Caring Sci. 2013; 27(2):406-13.

22. World Health Report 2008: Primary health care needed more than ever. OMS 2008. chapter 3. (Accessed September 24, 2018). Available from: http://www.who.int/whr/2008/08_report_es.pdf 23. Lamin E, Parillo L, Newman D, et al. Pelvic Floor Muscle Training: Underutilization in the USA. Curr Urol Rep. 2016; 17(10):1-7 24. Higa R, Rivorêdo CRSF, Campos LK, et al. Life experiences of Brazilian women with urinary incontinence. Texto contexto - enferm. 2010;19(4):627-35. 25. Van den Muijsenbergh M, Lagro-Janssen T. Urinary incontinence in Moroccan and Turkish women: a qualitative study on impact and preferences for treatment. $\mathrm{Br}$ J Gen Pract. 2006; 56: 945-9.

26. Government of Chile. Ministry of Health. Women's Health Program, Chile, Minsal,1997. (Accessed September 24, 2018). Available from: http://www.minsal.cl/wp-content/uploads/2015/09/Programa-de-Salud-de-la-Mujer1997.pdf

27. Byles JE. An evaluation of three community-based projects to improve care for incontinence- Int Urogynecol J 2005;16:29-38. 
28. Fasce E., Ortiz L. Attributes of professionalism estimated by medical students and doctors. Analysis using the lexical availability model. Re Med Chile 2009;137(6):746-52.

Figure 1 Model of determinants of seeking healthcare and remaining in the healthcare system for women with urinary incontinence.

This article is protected by copyright. All rights reserved. 
Table 1 Characteristics of the study population.

\begin{tabular}{|c|c|c|c|c|c|c|c|c|}
\hline Patient & Job & Age, y & $\begin{array}{l}\text { Educational } \\
\text { attainment }\end{array}$ & Marital status & $\begin{array}{l}\text { No. of } \\
\text { deliveries }\end{array}$ & Type of delivery & $\begin{array}{l}\text { Neonate weight, } \\
\mathrm{g}\end{array}$ & $\begin{array}{l}\text { Period before } \\
\text { seeking care }\end{array}$ \\
\hline \multirow[t]{2}{*}{11} & Vendor & 39 & $\begin{array}{l}\text { Unfinished } \\
\text { secondary }\end{array}$ & $\begin{array}{l}\text { Cohabits with } \\
\text { partner }\end{array}$ & 3 & Vaginal with episiotomy & 3950 & $19 \mathrm{y}$ \\
\hline & & & & & & $\begin{array}{l}\text { Vaginal with episiotomy } \\
\text { Cesarean }\end{array}$ & $\begin{array}{l}3840 \\
3100\end{array}$ & \\
\hline 12 & $\begin{array}{l}\text { Teacher/ } \\
\text { voluntary work }\end{array}$ & 33 & $\begin{array}{l}\text { Tertiary } \\
\text { (university) }\end{array}$ & $\begin{array}{l}\text { Single, without } \\
\text { partner }\end{array}$ & $\begin{array}{l}\text { No sexual } \\
\text { contact }\end{array}$ & & & $2 y$ \\
\hline \multirow[t]{3}{*}{13} & Housewife & 43 & Secondary & $\begin{array}{l}\text { Cohabits with } \\
\text { partner }\end{array}$ & 3 & Vaginal & 3100 & $5 y$ \\
\hline & & & & & & Vaginal & 2750 & \\
\hline & & & & & & Vaginal & 3000 & \\
\hline 14 & $\begin{array}{l}\text { Nursery } \\
\text { technician }\end{array}$ & 48 & $\begin{array}{l}\text { Tertiary } \\
\text { (technical } \\
\text { training) }\end{array}$ & $\begin{array}{l}\text { Single, without } \\
\text { partner }\end{array}$ & 1 & Vaginal with episiotomy & 3350 & $6 \mathrm{y}$ \\
\hline \multirow[t]{2}{*}{15} & $\begin{array}{l}\text { Nursery } \\
\text { technician }\end{array}$ & 53 & Secondary & $\begin{array}{l}\text { Single, without } \\
\text { partner }\end{array}$ & 2 & Vaginal with episiotomy & 4400 & $4 \mathrm{mo}$ \\
\hline & & & & & & Vaginal with episiotomy & Approx. 3000 & \\
\hline \multirow[t]{3}{*}{16} & Housewife & 46 & $\begin{array}{l}\text { Unfinished } \\
\text { secondary }\end{array}$ & Married & 3 & Vaginal with episiotomy & Approx. 3000 & $1.5 \mathrm{y}$ \\
\hline & & & & & & Vaginal with episiotomy & Approx. 3000 & \\
\hline & & & & & & Vaginal with episiotomy & Approx. 4000 & \\
\hline \multirow[t]{3}{*}{17} & $\begin{array}{l}\text { Domestic } \\
\text { worker }\end{array}$ & 52 & Primary & Separated & 3 & Vaginal with episiotomy & 4000 & $1 \mathrm{y}$ \\
\hline & & & & & & Vaginal with episiotomy & 4000 & \\
\hline & & & & & & Vaginal with episiotomy & 3250 & \\
\hline 18 & Housewife & 37 & Secondary & Married & 2 & Vaginal with episiotomy & $\begin{array}{l}3810 \\
3480\end{array}$ & $>1 \mathrm{y}$ \\
\hline 19 & Teacher & 41 & Tertiary & $\begin{array}{l}\text { Cohabits with } \\
\text { partner }\end{array}$ & 1 & Vaginal with episiotomy & 4800 & $6 \mathrm{y}$ \\
\hline 110 & Housewife & 42 & Primary & Married & 4 & $\begin{array}{l}\text { Vaginal delivery } \\
\text { Vaginal delivery } \\
\text { Forceps } \\
\text { Cesarean }\end{array}$ & $\begin{array}{l}\text { Approx. } 3000 \\
\text { Approx. } 4000 \\
\text { Approx. } 4000 \\
\text { Approx. } 4000\end{array}$ & $<1$ \\
\hline
\end{tabular}

This article is protected by copyright. All rights reserved. 
Table 2 Personal characteristics affecting healthcare seeking.
Characteristic
Enables healthcare seeking
Frequency and
An increase in the intensity of symptoms associated with
Hinders healthcare seeking
quantity of symptoms
involuntary urination making it necessary to seek health care
"...because I laugh a lot, so I noticed that I suffered many
To experience urine leakages in situations that do not affect daily [leakages.] So, I couldn't hold it like before - when I sneezed
or laughed, or needed to use more strength to do something, then a little leakage happened. It left me uneasy and worried" (I5)
"I sought help because it's too much now" (I1)
"I suffered leakages during the whole day" (I3)
"I [wet] myself, and when I was on the field l'd have to go
back, to change my pants... especially in summer, when I
drink the most water... so, I always keep clothes at my work
place, everything I could need" (14)
Uncertainty
Fear that their condition worsened - that is to say, that it
Not identified
would become a pathological condition with a worse
prognosis or that the symptoms intensified.
"... until I started taking it a little more seriously, "cause then I thought, 'I'm [going to] be on the streets and l'll [wet] myself"' (I8)
"I became afraid, when I thought that it could have been
some cancer of that sort" (19)
Beliefs in possible Not identified
"Urinary incontinence is only when I sneeze. No leakage when being intimate, so I feel pleasure" (I3)
To believe that their gynecologic problem is simply due to aging and vaginal births
causes
Not identified
Postponing
"I thought then that it was normal, and I didn't think much of it, due to my immaturity and youth" (I9)
"[lt surprised me], because grannies usually have it, but I never thought I'd end up with this so soon" (14)
Becoming accustomed to put their needs after those from other people in their lives.
"So you wet the bed and end up playing dumb - but it's still gross, the smell is not that of sex, it's different... I don't feel a thing" (I8) "I didn't think it was that necessary. I have little free time, usually on weekends - and Saturdays are for housework and Sundays for readying things for the work week" (19)
Developing coping strategies to lessen the symptoms and even

This article is protected by copyright. All rights reserved. 
changing some habits - emphasis on using pads, reducing the fluid intake and going only to places with a nearby bathroom.

"When I go downtown, I use several pads or keep another pair of panties in my purse, plus pads... For example, I try to drink more in the morning, so I spend it [wetting] myself - yesterday I changed clothes 3 or 4 times. I try not to drink anything when I go out" (I3)

"I'm always thinking of going to the bathroom, I'm really worried about [wetting] myself, for hygiene. It's pretty complicated. If I go to a restaurant, I must check whether there's a bathroom or not,

because l've to go there soon after a drink or a juice. So that's another worry for me" (I2)

This article is protected by copyright. All rights reserved. 
Table 3 Characteristics associated with environment (partner, family, friends, and coworkers).

\begin{tabular}{|c|c|c|}
\hline Characteristic & Enables healthcare seeking & Hinders healthcare seeking \\
\hline \multirow{4}{*}{$\begin{array}{l}\text { Reaction to } \\
\text { involuntary urination }\end{array}$} & Contempt & Apathy \\
\hline & $\begin{array}{l}\text { "So now they mock me, 'Hah, mom [wet] herself!' My children, they are } \\
\text { adults, but still mock me, 'Hah, mom [wet] herself!" (I3) }\end{array}$ & $\begin{array}{l}\text { "Well... No, I haven't talked too much about this with } \\
\text { him, because he isn't interested, he doesn't care." (I1) }\end{array}$ \\
\hline & "My partner does not take it seriously, too" (I3) & $\begin{array}{l}\text { "During sex, well, yes, he [kind of] cares, but visiting a } \\
\text { doctor? No, since men are like, they don't feel it, they } \\
\text { don't care about it" (I9) }\end{array}$ \\
\hline & $\begin{array}{l}\text { Social support } \\
\text { "I've talked about this with my children so that they are aware, and they } \\
\text { told me to just treat it. They take it lightly; we all laugh and talk about this, } \\
\text { so no problem there" (I5) } \\
\text { "... he knows that I come here for treatment. There's good communication } \\
\text { between us, we converse all things. He even supports this, tells me that } \\
\text { this is for your health" (I10) }\end{array}$ & \\
\hline
\end{tabular}

This article is protected by copyright. All rights reserved. 
Table 4 Characteristics associated with primary care.

\begin{tabular}{|c|c|c|}
\hline \multirow{3}{*}{$\begin{array}{l}\text { Characteristic } \\
\text { Human } \\
\text { resources }\end{array}$} & Enables healthcare seeking & Hinders healthcare seeking \\
\hline & A referring professional available in gynecologic care & Not identified \\
\hline & $\begin{array}{l}\text { "Since one doesn't know what to do, [l] went to the hospital, to } \\
\text { talk to the midwife. She explained to me that l'd have to be } \\
\text { referred here" (I7) } \\
\text { "I went to the Family Health Center, where a midwife assisted } \\
\text { me and then referred me here" (I1) }\end{array}$ & \\
\hline $\begin{array}{l}\text { Technical } \\
\text { resources }\end{array}$ & $\begin{array}{l}\text { Availability of preventive and promotional gynecological care } \\
\text { programs } \\
\text { "When it was time for a checkup with the midwife and the } \\
\text { routine examinations that go with it, then I told her about it and } \\
\text { I was referred here" (I10) } \\
\text { "I went for a Pap test. There, a midwife assisted me and I told } \\
\text { her the troubles I had" (I9) }\end{array}$ & Not identified \\
\hline $\begin{array}{l}\text { Delivery of } \\
\text { information }\end{array}$ & Not identified & $\begin{array}{l}\text { Lack of informative campaigns on pelvic floor dysfunctions for raising } \\
\text { awareness in the population at risk } \\
\text { "We need more info. I saw talks on incontinence only in the hospital, } \\
\text { and they should be in the community health centers, for the people } \\
\text { who are ashamed of this" (I10) }\end{array}$ \\
\hline
\end{tabular}
who are ashamed of this" (I10)

This article is protected by copyright. All rights reserved. 
Table 5 Characteristics associated with secondary care.

\section{Characteristic Enables healthcare seeking

Delivery of Giving information on the diagnosis and its \\ information \\ causes}

"The doctor told me that, since my bladder was like a deflated balloon, it accumulated too much when it was filled up, so it didn't hold and let out all the urine" (I2)

"They become loose, the thin elastics in the bladder as the doctors call them, and that's where incontinence comes from" (14)

Professionalism Renowned empathy and compromise from the of staff staff of the specialized unit

"She really connects with her patients. I can talk with her, ask any question, and as I say, to thank her... and well, l've still a session left, so yes, it's pretty good" (I5)

"The kinesiologist - she is the only one here and sees a lot of people, but she's excellent" (I10)

Waiting times Not identified
Hinders healthcare seeking

A short visit by the specialist

"I was assisted by a specialist, whose name I can't even recall, and I had to make all the questions. What do I have? What is that? What is the treatment for this? Do I need an operation for that? Though I also know that they have a workload that does not allow time to give information - sometimes, the patient enters, is assisted and is referred, without any more info" (I9)

Misguided notions of service that highlight the necessity of continuous training and excellence

"When the midwife saw me, she said that it was something merely esthetic. Since it wasn't affecting me when it came to the urine, there were no problems, so that was it. Then, after some time, when I started feeling pain, only then I visited the doctor" (I5)

The waiting time to get an appointment with the specialist and the failure to attend to their appointments in the unit.

"I also felt a bit confused, because initially I had an appointment on a certain date, and then it was changed due to the midwife supposedly being on vacation. When I came back again, they told me that no, it was not the midwife who I had to see, so I lost a month. They gave me a new appointment, but I didn't write it down so I forgot it and lost it. I came here once more last week. I've been a bit distressed by this and want to be done with it soon, but the secretary here told me that this would take at least a year in the public system and that left me nervous - I just want to have the operation soon" (I9)

"The topic of women is super important and so is improving waiting times. I put myself on the shoes of those with cancer - just imagine, they told me that I had to wait until January to get an appointment with the doctor" (I9)

"I have an appointment at 8 and soon it will be 9 o'clock, and I do know that there is only one kinesiologist, but..." (I10)

This article is protected by copyright. All rights reserved. 


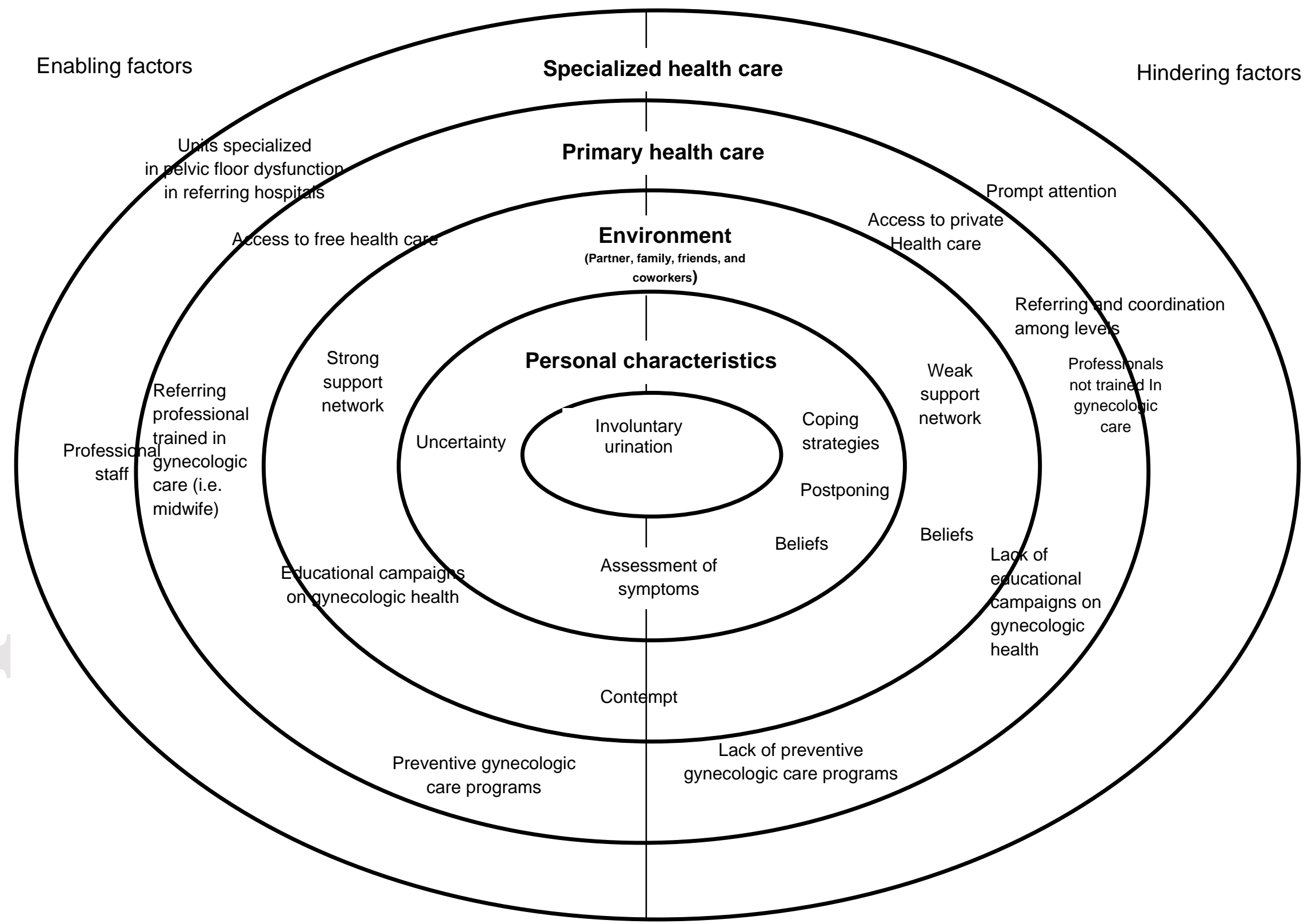

This article is protected by copyright. All rights reserved. 